\title{
Nakit Akış Döngüsünün Belirleyicileri: Türkiye İmalat Sanayi Örneği
}

\begin{tabular}{|c|c|}
\multicolumn{2}{|c|}{ Ersin YENISU $^{1}{ }^{1}$ Sedat $^{\text {YENICE }^{2}}$} \\
\hline$\frac{\text { Gönderim Tarihi }}{\mathbf{0 3 . 0 8 . 2 0 2 1}}$ & $\frac{\text { Kabul Tarihi }^{20.10 .2021}}{20.21}$ \\
\hline
\end{tabular}

Önerilen Atıf / Suggested Citation:

Yenisu, E. \& Yenice, S. (2022). Nakit Akış Döngüsünün Belirleyicileri: Türkiye İmalat Sanayi Örneği. Bankacılık ve Finansal Araştırmalar Dergisi, 9(1), 43-56.

$\ddot{O} z$

Nakit akış döngüsü son yıllarda işletmeler açısından daha da önem kazanmıştır. İşletmeler borçlarını zamanında ödeyebilmek ve faaliyetlerini kesintisiz olarak sürdürebilmek için mutlaka likiditelerini korumalıdırlar. Nakit yönetimi rekabetin iyice arttı̆̆ı günümüzde finansal fonların en iyi şekilde yönetilmesi için kritik bir öneme sahiptir. Geleneksel olarak işletmeler nakit akış süresini azaltmak için alacaklarını en kısa sürede temin etmeli, borçlarını firmanın imajını zedelemeyecek şekilde ötelemeli ve stok tutma sürelerini mutlaka azaltmalıdırlar. Bu doğrultuda çalışmada nakit aklş döngüsünü belirleyen işletme düzeyindeki unsurlar analiz edilmiştir. Çallşmada Borsa İstanbul (BIST)'da faaliyet gösteren 108 imalat sanayi şirketinin ylllı finansal verileri kullanılmıştır. Dönem olarak ise nispeten istikrarlı diyebileceğimiz 2010-2017 arası analiz edilmiştir. Diğer taraftan veriler hem kesit hem de zaman etkisi taşıdlı̆̆ için yöntem olarak dinamik bir tahminleme modeli olan Sistem GMM panel regresyon modeli kullanılmıştır. Yapılan korelasyon ve Sistem GMM analizleriyle nakit akış döngüsünü önceki dönem nakit akış süresinin ve aktif devir hızının etkilediği sonucuna varlmuşstır. Çalışmada veriler sektörlere ayrıştırılmış ve "tekstil" sektöründe nakit akış döngüsünün en uzun, "metal" sektöründe ise en kisa olduğu bulgulanmıștır. Sonuç olarak, bu çalışmaya göre işletmeler büyüdükçe nakit akış döngüsü süresi kısalmaktadır. Bu nedenle, özellikle küçük işletmeler finansal performanslarını arttırmak için alacak tahsil sürelerini azaltmaya, ortalama stok düzeylerini düşürmeye ve borçların daha uzun vadeye yaymaya önem vermelidirler.

Anahtar Kelimeler: Nakit Aklş Döngüsü, İmalat Sanayi, Sistem GMM

Jel Kodlart: C33, L25, M21

\section{Determinants of Cash Conversion Cycle: The Case of Turkey Manufacturing Industry}

\begin{abstract}
The cash conversion cycle has become more important in recent years. Firms must always maintain their liquidity in order to be able to pay their debts on time and to continue their activities without interruption. Cash management is critical importance for management of financial funds in today's competitive environment. Traditionally, firms should obtain their receivables as soon as possible, and should long their debts in such a way that they do not damage the image of the company, should reduce their stock hold period. In this study, business level factors that determine the cash conversion cycle are analyzed. The annual financial data of 108 manufacturing companies operating in Borsa Istanbul (BIST) are used. The period between 2010-2017 for relatively stable is analyzed. On the other hand, since the data has both cross-section and time effects, System GMM panel regression model, which is a dynamic estimation model, was used as a method. As a result of the correlation and System GMM analysis, it was concluded that the
\end{abstract}

\footnotetext{
${ }^{1}$ Ankara Hacı Bayram Veli Üniverstesi Gölbaşı Yerleşkesi Merkez Kütüphanesi, ersinyenisu@gmail.com, Orcid ID 0000-0002-0235-4270.

${ }^{2}$ Doç. Dr., Ankara Hacı Bayram Veli Üniverstesi Polatlı Sosyal Bilimler Meslek Yüksekokulu, sedatyenice@gmail.com, Orcid ID: 0000-0003-4232-329X
} 
cash conversion cycle in the previous period and the active turnover rate affected the cash conversion cycle. In the study, the data were divided into sectors and it was found that the cash conversion cycle was the longest in the "textile" industry and the shortest in the "metal" industry. As a result, as businesses grow, the cash conversion cycle time shortens. For this reason, especially small enterprises should pay attention to reducing their credit collection periods, decreasing their average inventory levels and spreading their debts for a longer term in order to increase their financial performance.

Keywords: Cash Conversion Cycle, Manufacturing, System GMM

Jel Codes: C33, L25, M21

\section{Giriş}

Nakit yönetimi işletme sermayesi yönetiminin en önemli unsurlarındandır. İşletmeler faaliyetlerini etkin olarak sürdürebilmek için nakit akış döngüsünü dikkakle izlemelidirler. Finans literatüründe nakit akış döngüsüne ilk olarak Richard ve Laughlin (1980) tarafından değinilmiştir. Söz konusu çalışmada nakit akış döngüsünün nasıl hesaplanacağı belirlenmiş ve bu yeni kavramın işletmenin likidite yönetiminde etkili olduğu savunulmuştur.

Richard ve Laughlin (1980)'in bu çalışmasından sonra, işletmelerin geleneksel amacı olan karlılık üzerinde nakit akış döngüsünün etkili olduğu ampirik araştırmalarla saptanmıştır (Yücel ve Kurt, 2002; Uyar, 2009; Nobanee, Abdullatif ve AlHajjar, 2011; Attari ve Raza, 2012; Anser ve Malik 2013; Karadağlı 2013; Takon 2013; Jamal, Waseem ve Khan 2014; John 2014; Valahzaghard ve Ghalhari, 2014; Yasir, Majid ve Yousaf, 2014; Yazdanfar ve Öhman, 2014; Garanina ve Petrova 2015; Mun ve Jang 2015; Upadhyay, Sen ve Smith 2015; Kaur ve Singh 2016; Oseifuah ve Gyekye, 2016; Zakari ve Saudi, 2016; Ali, Rahman ve Obaid, 2017; Chang, 2018; Cristea ve Cristea, 2018; Linh ve Mohanlingam, 2018; Rizky ve Mayasari, 2018 ve Samosir, 2018). Nakit akış döngüsü ile karlılık arasındaki ilişkiyi doğrulayan tüm bu çalışmalar nakit akış döngüsünün önemli bir likidite yönetimi aracı olduğunu kanıtlamıştır. Tüm bu nedenlerden dolayı nakit akış döngüsünün belirleyicilerini saptamak önem kazanmaktadır. Bununla birlikte literatürde nakit akış döngüsünün sektörel anlamda Uyar (2009) incelemiştir. Uyar (2009) çalışmasında nakit akış döngüsünün tekstil sektöründe en yüksek (164,89 gün), perakende sektöründe en düşük $(34,58$ gün) olduğunu bulgulamıştır. Bu çalışma ise nakit akış döngüsünün belirleyicilerini açıklamayı ve sektörlerde farklılaşma olup olmadığını ortaya koymayı amaçlamaktadır.

Nakit akış döngüsü (NAD) işletme yönetiminin etkinliğini ve işletmenin gerçek anlamda dış kaynak ihtiyacını belirlemekte sıklıkla kullanılır (Wang, 2019). Nakit akış döngüsü akademik çalışmalarda genellikle işletme sermayesi yönetimi ve tedarik zinciri etkinliği açılarından araştırılmaktadır (Talonpoika, Monto, Pirtilla ve Karri, 2013). Ruyken (2011) çalışmasında etkin ve verimli bir tedarik zinciri yönetiminin firmanın nakit döngüsünü hızlandırdığını ve sermayenin serbest bırkakıldığını bulgulamışttır.

Literatürde nakit akış döngüsünün unsurlarını inceleyen çok az sayıda çalışma vardır. Mathuva (2014) Kenya'daki finansal kurumlar dışındaki firmalar üzerine yaptığı çalışmada genel olarak işletmelerin hedef bir NAD belirlediklerini bulgulamıştır. Ayrıca, söz konusu çalışmayla aktif karlılığı, sermaye yatırımları harcamaları ve büyüme firsatları ile NAD arasında negatif yönlü; enflasyonla NAD arasında pozitif yönlü bir ilişki olduğu sonucuna varılmıştır. Diğer taraftan Kores ve Manikas (2014)'a göre nakit akış döngüsü ile firma performansı ilişkili değildir. Bununla birlikte yapılan çalışmalarda işletmelerin optimum nakit akış döngüsünü sağlayıp sağlamadıkları da ölçülmüştür. Nitekim, Konuk ve Zeren (2014) Türkiye'de faaliyet gösteren gıda-içecek firmaları üzerinde yaptıkları araştırmada söz konusu işletmelerde dengeli bir işletme sermayesi politikasının olmadığını ortaya koymuşlardır. Diğer yandan, bu çalışmanın analiz konusu olan Türkiye istikrarsızların belirgin olduğu gelişmekte olan bir ülkedir. Nihayetinde elde edilen bulgular bu durum dikkate alınarak değerlendirilmelidir. 
Bununla birlikte, nakit akış döngüsü şirketin likiditesini dinamik olarak ölçmekte ve aynı zamanda şirketin performansı hakkında da bilgi sağlamaktadır (Bolek, Kacprzyk ve Wolski, 2012). Nakit akış döngüsü genellikle finansal yöneticilerin işletme sermayesi yönetimiyle ilişkilidir. Bhutto (2011)'e göre agresif ya da muhafazakar işletme sermayesi yönetimi ile nakit akış dögüsü arasında yakın bir ilişki vardır. Diğer taraftan, nakit akış döngüsü küçük işletmelerde de dikkatle izlenmesi gereken bir süreçtir. ABD'deki küçük işletmeler üzerine yaptıkları araştırmada Ebben ve Johnson (2011) firma sahiplerinin nakit yönetiminde daha duyarlı olmalarının gerekliliğini vurgulamışlardır. Bir diğer çalışma olan Yücel ve Kurt (2002)'a göre nakit akış döngüsü imalat işletmelerinde hizmet işletmelerinden daha uzundur. Buna ek olarak, küçük firmalarda nakit akış döngüsünü inceleyen Lyroudi ve McCarty (1993)'e göre ise nakit akış döngüsü yine sektörel anlamda farkl1lık göstermektedir.

Nakit akış döngüsü literatürde farklı açılardan da incelenmiştir. Fakat bu çalışmanın da esas konusu olan nakit akış döngüsünün belirleyicilerine sınırlı sayıda çalışma değinmiştir (Lyroudi ve McCarty, 1993, Mathuva, 2014). Nitekim, çalışmanın farklılığı ekonometrik analizde nakit akış döngüsünü bağımsız değil bağımlı değişken olarak alınmasıdır. Ayrıca, sektörler arası farklılıkları inceleyen çalışma bu yönüyle literatüre katkıda bulunabilir. Çalışmanın önemi ise nakit akış döngüsü üzerinde karlılık ve işletmelerle ilgili olan daha birçok kantitatif göstergenin etkinliğinin saptanmış olmasıdır.

Çalışma beş bölümden oluşmaktadır. İlk bölüm giriş kısmına, ikinci bölüm nakit akış döngüsünün teorik açıklamasına, üçüncü bölüm kullanılan veri seti ve kapsama, dördüncü bölüm analiz ve bulguların değerlendirilmesine ve son olarak beşinci bölüm de çalışmanın bulgularının özetlendiği sonuç kısmına ayrılmıştır.

\section{Nakit Akış Döngüsü}

Finans literatüründe etkin işletme sermayesi yönetiminin önemi tartışılmazdır. İşletme sermayesi yönetiminin amacı, işletme sermayesi bileşenlerinin her birinin optimum dengesini sağlamaktır (Filback ve Kruger, 2005). Enqvist, Graham ve Nikkinen (2014) çalışmalarında aktif işletme sermayesi yönetiminin önemli olduğunu ve dolayısıyla firmaların finansal planlamasına dahil edilmesi gerektiği sonucuna ulaşmışlardır. Benzer şekilde Şen ve Oruç (2009)'a göre finans literatüründe işletme sermayesi yönetiminin önemi hakkında ortak bir görüş vardır. Bir işletme için işletme sermayesi yönetiminin neden önemli olduğu ile ilgili açıklamalar genellikle işletme sermayesi yönetiminde verimlilik ile firma karlılığı arasındaki ilişkiye odaklanır. Yukarıda da değinildiği gibi işletme sermayesi üst bir kavramdır ve alt birimlere ayrılır. Deloof (2003) işletme sermayesi yönetiminin popüler bir ölçüsü nakit akış döngüsü olduğunu ve bunun da hammadde alımları için yapılan harcama ile mamullerin satışları arasındaki süre olduğunu açıklamıştır. Deloof (2003)'a göre bu süre uzadıkça, işletme sermayesine yapılan yatırım da artar. Kısacası nakit akış döngüsü stratejik bir unsur olan işletme sermayesi yönetiminde önemli bir yere sahiptir. Nitekim likidite yönetimi, çoğu kez finansal yönetimde ihmal edilen bir husus olsa da, bir finansal yöneticinin zamanının ve dikkatinin büyük bir bölümünü kaplar (Wang 2002).

Nakit akış döngüsü, bir firmanın satış düzeyini arttırmak için kaynaklara (örneğin stoklara) yatırımını artırdığında, söz konusu firmanın nakitten mahrum kaldığı süreyi gösteren bir likidite risk ölçüsüdür (Mathuva, 2014). Nakit akış döngüsü tahakkuk eden muhasebe bilgilerine dayanmaktadır ve dolaylı olarak bir firmanın değerlemesi ile ilgilidir. Yani, uzun bir nakit akış döngüsü karşısında kısa bir nakit akış döngüsü, genellikle tedarikçiye vadesine yakın bir zamanda ödeme yaparken firmanın hızlı bir şekilde nakit aldığını gösterir (Gentry, Vaidyanathan ve Lee, 1990). Yine Gentry, Vaidyanathan ve Lee (1990)'ye göre likidite analizinde geleneksel ve statik bir analiz aracı olan cari oran kullanılmaktadır. Nakit akış döngüsüyse daha dinamik bir yöntemdir ve uzun bir süredir kullanılmaktadır. İşletme yönetiminde içgüdüsel değil rasyonel kararların alınması açısından nakit akış döngüsü yaklaşımı önemlidir. Richard ve Laughlin (1980), çalışma sermayesi yönetimine yapılan nakit dönüşümü yaklaşımının, likidite konusunda 
sezgisel değerlendirmenin potansiyel tehlikesini gösterdiğinin ifade etmişlerdir. Nakit akış döngüsünün işleyişi Şekil 1'de gösterilmiştir.

Şekil 1. Nakit Akış Döngüsü

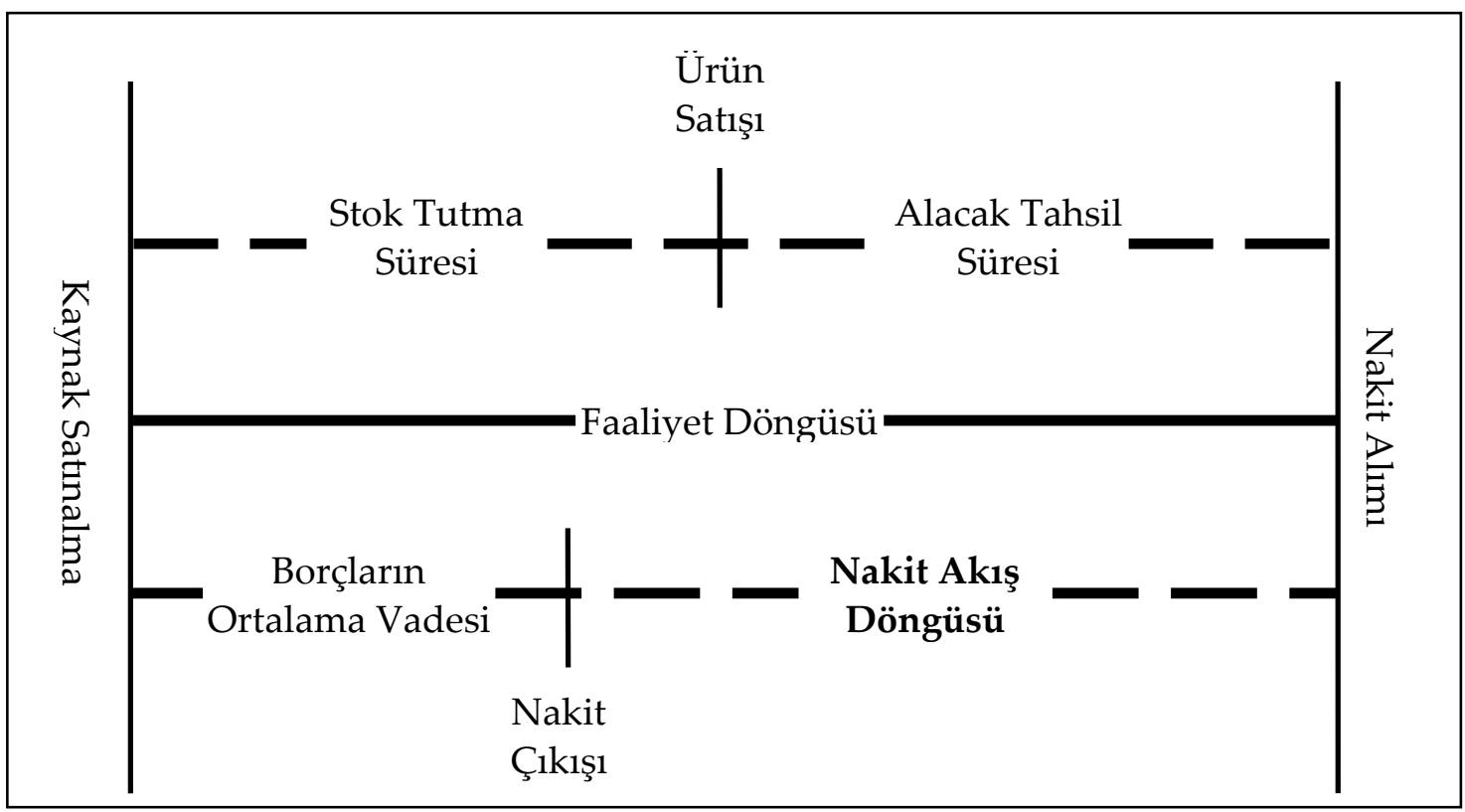

Kaynak: Richards ve Laughlin (1980)

Şekil 1'deki döngünün bir diğer gösterimi şöyledir:

Nakit Akış Döngüsü (NAD)= Alacak Tahsil Süresi (ATS) + Stok Tutma Süresi (STS) - Borçların Ortalama Vadesi (BOV)

Literatürdeki yaygın kanaate göre nakit akış döngüsü süresi ne kadar kısalırsa firmanın likidite ve karlılık düzeyi o kadar iyileşmektedir. Bu doğrultuda nakit akış döngüsü belirleyen finansal etkenlerin saptanması önem kazanmaktadır. Lyroudi ve McCarty (1993), çalışmalarında nakit akış döngüsü belirleyicilerinin gerek firma büyüklüğü açısından gerek sektörel anlamda farklılıklar taşıdığını bulgulamışlardır. Bu çalışmada da yukarıdaki çalışmalarda belirtilen değişkenlerin, belirlenen diğer finansal değişkenlerin ve sınıflandırmaların (firma büyüklüğü ve sektörler açısıdan) nakit akış döngüsü üzerindeki etkileri araştırılacaktır.

\section{Veri Seti ve Kapsam}

Bu çalışmada Borsa İstanbul (BIST) imalat sanayi şirketlerinin mali tablolarından elde edilen veriler kullanılmıştır. Bu kapsamda toplam 157 şirketin verilerine ulaşılmıştır. Daha sonra, 157 şirket arasından eksik veri olmayan 108 şirket analize dahil edilmiştir. Çalışmada söz konusu şirketlerin bilanço ve gelir tablolarının yıl sonu değerleri esas alınmıştır. Seçilen dönem aralığ veri erişebilirliği ve uygunluk nedeniyle 2010-2017 olarak belirlenmiştir. Kırılgan bir ekonomiye sahip olan Türkiye ekonomisinde söz konusu yıllar nispeten istikrarlıdır. Nitekim bu dönem aralığının seçilme sebebi metodolojik bir sorun olan yapısal kırılma ihtimalini azaltmaktır. Analizlerde kullanılan 11 temel değişken; Alacak Devir Hızı (ADH), Stok Devir Hızı (SDH), Borç Devir Hızı (BDH), Net İşletme Sermayesi (NIS), Brüt Satışlar, Toplam Aktifler, Faiz ve Vergi Öncesi Kar (FVÖK), Ner Kar (Zarar), Özsermaye ve Net Satışlar' dır. Çalışmada panel veri analizi için toplam 9504 adet gözlem bulunmaktadır.

Analizlerde kullanılan veri seti tanımlamaları ve hesaplamaları şöyledir: 
Nakit Akış Döngüsü (NAD)

Özsermaye Karlılığı $(\mathrm{OK})=\frac{\text { Net Kar }}{\text { Özsermaye }}$

Aktif Karlılı̆̆ $(\mathrm{OK})=\frac{\text { Net Kar }}{\text { Toplam Aktifler }}$

Faiz ve Vergi Öncesi Kar Devir Hızı (FVOKDH) $=\frac{\text { Net Satışlar }}{\text { FVÖK }}$

Net İşletme Sermayesi Devir Hızı (NISDH) $=\frac{\text { Net Satışlar }}{\text { Net İşletme Sermayesi }}$

Özermaye Devir Hızı $(\mathrm{ODH})=\frac{\text { Net Satışlar }}{\text { Özsermaye }}$

Aktif Devir Hızı $(\mathrm{ADH})=\frac{\text { Net Satışlar }}{\text { Toplam Aktfiler }}$

Çalışmada kullanılan veriler "Finnet" veri tabanından temin edilmiştir. Analizlerde Excel, SPSS ve Stata paket programlarından yararlanılmıştır. Daha sonraki bölümde de görüleceği üzere çalışmada 108 şirket sektörel olarak ayrıştırılmış ve sektörlerdeki değişim ya da farklılıklar da gözlemlenmeye çalışılmıştır.

\section{Analiz ve Bulgular}

Çalışmada kullanılan veri seti hem zaman hem de kesit etkisi içerdiği için panel veri analizi tercih edilmiştir. Panel veri analizi daha fazla sayıda örneklem içermesi nedeniyle standart zaman serisi analizlerinden daha güvenilir sonuçlar vermektedir. Bu bölümde öncelikle değişkenler arasındaki ilişkinin yönünü ve gücünü açıklayan korelasyon analizi yapılacaktır. Daha sonra verilere Sistem GMM panel regresyon analizi uygulanacaktır. Söz konusu analiz yöntemi bağımlı değişkenin gecikmeli değerini bağımsız değişkenlerden biri olarak kabul eden dinamik bir model olduğu için tercih edilmiştir.

Korelasyon analizi sonuçları Tablo 1'de verilmiştir.

Tablo 1. Korelasyon Analizi

\begin{tabular}{|c|c|c|c|c|c|c|c|c|}
\hline & & NAD & OK & AK & FVOKDH & NISDH & ODH & ADH \\
\hline \multirow[t]{3}{*}{ NAD } & Pearson Korelasyon & 1 & 0,037 & $-0,086^{*}$ & 0,012 & $-0,044$ & $-0,081^{*}$ & $-0,403 * *$ \\
\hline & [Olasılık] & & {$[0,278]$} & {$[0,011]$} & {$[0,724]$} & {$[0,197]$} & {$[0,018]$} & {$[0,000]$} \\
\hline & $\mathbf{N}$ & 864 & 864 & 864 & 864 & 864 & 864 & 864 \\
\hline \multirow[t]{3}{*}{ OK } & Pearson Korelasyon & - & 1 & $0,145^{* *}$ & 0,006 & 0,022 & $-0,981 * *$ & 0,020 \\
\hline & [Olasılık] & & & {$[0,000]$} & {$[0,854]$} & {$[0,511]$} & {$[0,000]$} & {$[0,557]$} \\
\hline & $\mathbf{N}$ & & 864 & 864 & 864 & 864 & 864 & 864 \\
\hline \multirow[t]{3}{*}{ AK } & Pearson Korelasyon & - & - & 1 & 0,009 & $0,080 *$ & $-0,066$ & 0,192 \\
\hline & [Olasılık] & & & & {$[0,785]$} & {$[0,018]$} & {$[0,052]$} & {$[0,000]$} \\
\hline & $\mathbf{N}$ & & & 864 & 864 & 864 & 864 & 864 \\
\hline \multirow{3}{*}{\multicolumn{2}{|c|}{$\begin{array}{l}\text { FVOKADH Pearson Korelasyon } \\
\text { [Olasılık] } \\
\mathbf{N}\end{array}$}} & - & - & - & 1 & 0,006 & $-0,005$ & $-0,028$ \\
\hline & & & & & & {$[0,867]$} & {$[0,892]$} & {$[0,417]$} \\
\hline & & & & & 864 & 864 & 864 & 864 \\
\hline \multirow[t]{3}{*}{ NISDH } & Pearson Korelasyon & - & - & - & - & 1 & $-0,008$ & $0,097 * *$ \\
\hline & [Olasılık] & & & & & & {$[0,808]$} & {$[0,004]$} \\
\hline & $\mathbf{N}$ & & & & & 864 & 864 & 864 \\
\hline \multirow[t]{2}{*}{ ODH } & $\begin{array}{l}\text { Pearson Korelasyon } \\
\text { [Olasılık] }\end{array}$ & - & - & - & - & - & 1 & $\begin{array}{l}0,070^{*} \\
{[0,039]}\end{array}$ \\
\hline & $\mathbf{N}$ & & & & & & 864 & 864 \\
\hline ADH & $\begin{array}{l}\text { Pearson Korelasyon } \\
\text { [Olasilık] }\end{array}$ & - & - & - & - & - & - & 1 \\
\hline
\end{tabular}


**,* sirasiyla \% 1 ve \% 5 önem seviyesinde anlamlı.

Tablo 1'e göre nakit akış döngüsü ile aktif devir hızı arasında negatif yönlü ve güçlü bir ilişki vardır. Yine nakit akış döngüsü ile aktif karlılı̆̆ 1 ve özsermaye devir hızı arasında negatif yönlü istatistiksel olarak anlamlı bir ilişki vardır. Fakat aktif karlılı̆̆ 1 ve özsermaye devir hızı ile nakit akış döngüsü arasındaki negatif yönlü ilişki çok zayıftır. Bununla birlikte aktif devir hızı ile nakit akış döngüsü arasındaki illişki nispeten daha kuvvetlidir.

Korelasyon analizinden sonra dinamik bir tahminleme modeli olan Sistem GMM panel regresyon analizi yapılacaktır. Tahmin edilen modellerin doğrusal denklemleri şöyledir:

Model 1:NAD $D_{i t}=c_{i t}+N A D(-1)_{i t}+O K_{i t}+A K_{i t}+F V O ̈ K D H_{i t}+N I S D H_{i t}+O D H_{i t}+A D H_{i t}+e_{i t}$

Model 2:NAD $D_{i t}=N A D(-1)_{i t}+O K_{i t}+A K_{i t}+F V O ̈ K D H_{i t}+N I S D H_{i t}+O D H_{i t}+A D H_{i t}+e_{i t}$

Model 3:NAD $D_{i t}=c_{i t}+O K_{i t}+A K_{i t}+F V O ̈ K D H_{i t}+N I S D H_{i t}+O D H_{i t}+A D H_{i t}+e_{i t}$

Model 4:NAD $D_{i t}=c_{i t}+N A D(-1)_{i t}+F V O ̈ K D H_{i t}+N I S D H_{i t}+O D H_{i t}+A D H_{i t}+e_{i t}$

Model 5: $N A D_{i t}=c_{i t}+N A D(-1)_{i t}+O K_{i t}+A K_{i t}+e_{i t}$

Burada beş ayrı modelin tahmin edilme sebebi elde edilen bulguların sağlamlığını arttırmaktır. Görüleceği üzere her bir modelin tahmin sonuçları hemen hemen aynı yönü işaret etmektedir. Analiz sonuçlarının tutarlılı̆̆ açısından beş modelli yaklaşım önemlidir. Nitekim bu sayede karşılaştırmalar yapılabilecek ve bulgular daha nesnel olarak değerlendirilebilecektir. Dahası bu beş model aracılı̆̆ıyla model kurma hatasının önüne bir ölçüde geçilebilir ve diğer ekonometrik diagnostic (tanısal) testlere ilişkin sonuçların kabul edilebilirliği kuvvetlendirilebilir.

Yukarıdaki korelasyon analizi sonuçlarına göre aktif devir hızı güçlü bir şekilde, aktif karlılığı ve özsermaye devir hızı zayıf bir şekilde nakit akış döngüsü üzerinde etkilidir. Aşağıdaki panel regresyon analizi bulgularının da bu sonucu desteklemesi beklenmektedir.

Yukarıdaki eşitliklerden oluşan modellerin Sistem GMM panel regresyon analizi tahmin sonuçları Tablo 2'de sunulmuştur.

Tablo 2. Sistem GMM Panel Regresyon Sonuçları

\begin{tabular}{|c|c|c|c|c|c|}
\hline \multirow{2}{*}{$\begin{array}{l}\text { Bağımsız } \\
\text { Değişkenler }\end{array}$} & \multicolumn{5}{|c|}{$\begin{array}{l}\text { Bağımlı } \\
\text { Değisken: NAD }\end{array}$} \\
\hline & Model 1 & Model 2 & Model 3 (GLS) & Model 4 & Model 5 \\
\hline Sabit (C) & $\begin{array}{l}79.83765^{* * * *} \\
{[4.31]}\end{array}$ & - & $\begin{array}{l}204.4392 * * * \\
{[18.02]}\end{array}$ & $\begin{array}{l}62.53187 * * * \\
{[3.35]}\end{array}$ & $\begin{array}{l}4.246478 \\
{[1.28]}\end{array}$ \\
\hline NAD(-1) & $\begin{array}{l}0.9530642 * * * \\
{[27.24]}\end{array}$ & $\begin{array}{l}0.9541579 * * * \\
{[26.39]}\end{array}$ & - & $\begin{array}{l}0.9936633^{* * *} \\
{[29.35]}\end{array}$ & $\begin{array}{l}1.008994^{* * *} \\
{[45.21]}\end{array}$ \\
\hline OK & $\begin{array}{l}8.01417 \\
{[0.224]}\end{array}$ & $\begin{array}{l}3.759608 \\
{[0.68]}\end{array}$ & $\begin{array}{l}-16.71058 * * \\
{[-2.01]}\end{array}$ & - & $\begin{array}{l}-0.5020247 * * * \\
{[-3.73]}\end{array}$ \\
\hline AK & $\begin{array}{l}-134.4392 * * * \\
{[-4.55]}\end{array}$ & $\begin{array}{l}-103.4494 * * * \\
{[-3.53]}\end{array}$ & $\begin{array}{l}15.38008 \\
{[0.43]}\end{array}$ & - & $\begin{array}{l}-104.4542 * * * \\
{[-4.26]}\end{array}$ \\
\hline FVOKDH & $\begin{array}{l}-0.0027541 \\
{[-0.28]}\end{array}$ & $\begin{array}{l}0.0011269 \\
{[0.12]}\end{array}$ & $\begin{array}{l}-0.0134986^{* * * *} \\
{[-3.40]}\end{array}$ & $\begin{array}{l}-0.0084973 \\
{[-0.97]}\end{array}$ & - \\
\hline NISDH & $\begin{array}{l}-0.0059374 \\
{[-0,34]}\end{array}$ & $\begin{array}{l}-0.0069257 \\
{[0.701]}\end{array}$ & $\begin{array}{l}-0.0181913 \\
{[0.37]}\end{array}$ & $\begin{array}{l}-0.0044662 \\
{[-0.25]}\end{array}$ & - \\
\hline ODH & $\begin{array}{l}0.852034 \\
{[1.33]}\end{array}$ & $\begin{array}{l}0.4464844 \\
{[0.409]}\end{array}$ & $\begin{array}{l}-1.646089 * * \\
{[-2.03]}\end{array}$ & $\begin{array}{l}0.0740147 * * * \\
{[5.14]}\end{array}$ & - \\
\hline
\end{tabular}




\begin{tabular}{llllll} 
& $-77.26287 * * *$ & $-55.62621 * * *$ & $-85.00744 * * *$ & $-68.72695 * * *$ & - \\
ADH & {$[-4.55]$} & {$[-3.57]$} & {$[-8.90]$} & {$[-3.87]$} & \\
\hline Wald $x x^{2}$ & $1745.48(0,000)$ & $1685.75(0,000)$ & $108.94(0.000)$ & $1592.08(0.000)$ & $2295.90(0.000)$ \\
$($ Prob) & $36.085(0,090)$ & $30.003(0.268)$ & - & $41.85(0.025)$ & $34.78159(0.1165)$ \\
Sargan $x x^{2}$ & $-2.5413(0,011)$ & $-2.3806(0.017)$ & - & $-2.6095(0.009)$ & $-2.4968(0.013)$ \\
(Prob) & $-2.2916(0.022)$ & $-2.2061(0.027)$ & - & $-1.9929(0.046)$ & $-2.0845(0.037)$ \\
AR(1) & 756 & 756 & 864 & 756 & 756 \\
AR(2) & & & \\
Gözlem & & & \\
****** sirasiyla \% 1, \% 5 ve \% 10 önem seviyesinde anlamli. Köşeli parantez içindeki değerler z \\
istatistikleri, ayraçlar içerisindeki değerler olasilik değerleridir.
\end{tabular}

Tablo 2'de farklı bağımsız değişken setlerinden oluşan beş ayrı model tahmin edilmiştir. Söz konusu modellerdeki bağımlı değişken ise nakit akış döngüsü (NAD)'dür. Diğer taraftan klasik panel regresyon modeli (GLS) olan Model 3'te gözlem sayıs1 864; Sistem GMM panel regresyon modelleri olan Model 1, Model 2, Model 4 ve Model 5'te gözlem sayıs1 756'dır. Tanısal test sonuçlarına göre modellerin açıklama gücünün kabul edilebilir seviyede olduğu söylenebilir. Bulgular nakit akış döngüsünün bir gecikmeli değerinin bağımlı değişkeni açıklamada büyük öneme sahip olduğunu göstermektedir. Nitekim NAD(-1) değişkeni bütün modellerde istatistiksel açıdan anlamlıdır. Sonuç olarak işletmelerin nakit akış döngüsü süreleri büyük ölçüde bir önceki dönem nakit akış döngüsü sürelerine bağlıdır.

Yukarıdaki beş model arasından açıklama gücü en yüksek olan eşitlik Model 1'dir. Söz konusu modele göre nakit akış döngüsünün en önemli belirleyicisi yine bir önceki dönem nakit akış döngüsü süresidir. Diğer taraftan Model 1'e göre aktif karlılığı ve aktif devir hızı nakit akış döngüsünü negatif yönlü ve istatistiksel açıdan anlamlı olarak etkilemektedir. Tablo 2'den elde edilen bulgulara göre nakit akış döngüsü üzerinde aktif yönetiminin ya da aktif büyüklüğünün önemli bir etkisi bulunmaktadır. Diğer bir ifadeyle işletme büyüklüğü nakit yönetiminde kritiktir.

Tablo 3’te ise nakit akış döngüsünü belirleyen süreler sektörel olarak ayrıştırılmıştır.

Tablo 3. Sektörlere Göre Nakit Akış Döngüsü

\begin{tabular}{llllll}
\hline SEKTÖR (N) & NAD & ATS & STO & BOV & $\begin{array}{l}\text { TOPLAM } \\
\text { AKTIFLER (TL) }\end{array}$ \\
\hline Metal (9) & 87,8 & 61,91 & 84,3 & 58,3 & 2.514 .643 .454 \\
Kimya (15) & 106,8 & 106,4 & 70,2 & 69,8 & 2.361 .864 .229 \\
Makine (24) & 108,3 & 99,3 & 92,6 & 83,6 & 1.835 .082 .510 \\
Gida (18) & 119,3 & 87,9 & 106 & 74,4 & 1.968 .261 .262 \\
Kağıt (10) & 126,8 & 120,8 & 72,0 & 66 & 291.028 .752 \\
Çimento (20) & 132 & 97,6 & 92,7 & 58,2 & 880.935 .537 \\
Ormancılık (2) & 144.4 & 86 & 139,3 & 80,9 & 262.222 .578 \\
Tekstil (9) & 169,1 & 82,5 & 159,6 & 73,1 & 295.194 .596 \\
\hline ORTALAMA & $\mathbf{1 0 6 , 2}$ & $\mathbf{9 2 , 8}$ & $\mathbf{1 0 2}$ & $\mathbf{7 0 , 5}$ & $\mathbf{1 . 3 0 1 . 1 5 4 . 1 1 5}$ \\
\hline
\end{tabular}

Tablo 3'te analizlere dahil edilen 108 firma sektörel ayrıştırmaya tabi tutulmuştur. Söz konusu işletmelerin 9'u metal sektörüne, 15'i kimya sektörüne, 24'ü makine sektörüne, 18'i gıda sektörüne, 10'u kağıt sektörüne, 20'si çimento sektörüne, 2'si ormanc1lık sektörüne ve 9'u tekstil 
sektörüne aittir. Yukarıdaki panel veri analizinde incelenen bir işletme ise bu sektör sinıflandırmasına dahil değildir.

En düşükten en yükseğe doğru sektörlerdeki nakit akış süreleri; metal $(87,8)$, kimya $(106,8)$, makine $(108,3)$, gıda $(119,3)$, kağıt $(126,9)$, çimento $(132)$, ormancılık $(144,4)$ ve tekstil $(169,1)$ 'dir. Buna göre nakit akış döngüsü süresi metal sektöründe en azdır. Tekstil sektöründe ise en fazladır. Diğer taraftan "tekstil" sektöründe nakit akış döngüsü süresinin nispeten yüksek olmasının nedeni söz konusu sektörde stok tutma oranının diğer sektörlere göre yüksek olmasından kaynaklanmış olabilir. En düşük nakit akış döngüsü süresinin söz konusu olduğu "metal" sektöründe ise alacak tahsil süresinin nispeten düşük olduğu göze çarpmaktadır.

Ortalama değerler dikkate alındığında ise nakit akış döngüsü süresi açısından sadece "metal" sektörünün ortalamanın altında olduğu görülmektedir. Diğer yedi sektörde ise nakit akış süreleri ortalamanın üzerindedir. Sektörel ayrıştırma toplam aktif büyüklüğü açısından değerlendirilir ise genel olarak ortalama toplam aktifler arttıkça nakit akış döngüsü süresinin azaldığı söylenebilir. Nitekim siralamada ilk dört grupta toplam aktifler ortalama toplam aktif büyüklüğünün üzerindedir. Son dört grupta ise toplam aktiflerin ortalama toplam aktif büyüklügünün altında olduğu görülmektedir.

Analizde kullanılan verilerin Sistem GMM panel regresyon yaklaşımıyla sektörel olarak incelenmesi Tablo 4'te sunulmuştur. 
Tablo 4. Sistem GMM Sektörel Panel Regresyon Sonuçları

\begin{tabular}{|c|c|c|c|c|c|c|c|c|}
\hline \multirow{2}{*}{$\begin{array}{l}\text { Bağımsız } \\
\text { Değişkenler }\end{array}$} & \multicolumn{8}{|c|}{ Bağımlı Değişken: NAD } \\
\hline & Metal & Kimya & Makine & Gida & Kăğıt & Çimento & Ormancilık & Tekstil \\
\hline & & 4.383671 & $174.8042 * * *$ & 31.91679 & & 0.2253676 & & 21.30382 \\
\hline \multirow[t]{2}{*}{ Sabit (C) } & - & {$[68.38181]$} & [4.215157] & {$[43.8153]$} & - & [19.14994] & - & {$[424.45]$} \\
\hline & 0.7230217 & $0.6614302 * * *$ & $0.8537359 * * *$ & $0.7681126^{* * *}$ & $0.7427686^{* * *}$ & $0.8584635^{* * *}$ & -3.442427 & $0.5501348 * *$ \\
\hline \multirow[t]{2}{*}{ NAD(-1) } & {$[0.4500899]$} & {$[0.0965711]$} & {$[0.0295885]$} & {$[0.1062284]$} & {$[0.2276596]$} & [0.0303994] & {$[4.12447]$} & {$[0.2401878]$} \\
\hline & $-300,8123 * *$ & -10.00747 & -3.808321 & 56.73013 & -475.7902 & 18.25898 & & -394.988 \\
\hline \multirow[t]{2}{*}{ OK } & [149.7234] & [81.79744] & [16.59359] & [81.13938] & [444.6796] & [159.2667] & - & {$[520.3272]$} \\
\hline & 742.4884 & -243.0818 & $-173.2237 * * *$ & -78.30715 & -498.8037 & -43.93387 & & 878.2944 \\
\hline \multirow[t]{2}{*}{ AK } & {$[482.7234]$} & [291.2922] & {$[32.64678]$} & [70.52639] & {$[684.4123]$} & {$[230.2995]$} & - & {$[763.7055]$} \\
\hline & 0.1393594 & $-0.1317936^{* * *}$ & -0.0083234 & $-0.1325601 * * *$ & -0.167654 & 0.2143403 & -0.8497186 & 0.051515 \\
\hline \multirow[t]{2}{*}{ FVOKDH } & {$[0.1620365]$} & {$[0.0473211]$} & [0.091726] & [0.0097026] & [0.1845353] & [0.1395846] & {$[1.018756]$} & [0.7458917] \\
\hline & -1.155484 & $-0.0453258 * * *$ & -0.0145875 & 0.30729 & -5.251889 & 0.0763065 & & -20.21382 \\
\hline \multirow[t]{2}{*}{ NISDH } & [1.470349] & {$[0.0150971]$} & {$[0.0575305]$} & [0.3399199] & [5.179249] & [0.0472045] & & [18.30598] \\
\hline & $6.423747^{*}$ & $-13.97067 * * *$ & -6.288344 & 12.77698 & -45.91309 & $-60.84174 * * *$ & & 5.132514 \\
\hline \multirow[t]{2}{*}{ ODH } & [3.421954] & [4.299085] & [5.927496] & [14.99859] & [42.96711] & [21.33693] & & [43.93468] \\
\hline & -72.09736 & $127.5838 * * *$ & $108.6687 * * *$ & $-41.16973 * * *$ & 422.8087 & $76.19208 * * *$ & & 124.3135 \\
\hline ADH & [90.3864] & [40.93211] & [12.00199] & [12.49467] & [540.3119] & [22.92854] & & [818.9494] \\
\hline Wald $x x^{2}$ & $535.77(0.00)$ & $461.34(0.00)$ & $17790.75(0.00)$ & $25050.71(0.00)$ & $260.60(0.00)$ & $158304(0.00)$ & $0.71(0.6995)$ & $21.63(0.00)$ \\
\hline Sargan $x x^{2}$ & $0.785(1.00)$ & $4.74(1.00)$ & $15.81(0.94)$ & $8.33(1.00)$ & $2.27(1.00)$ & $17.99(0.88)$ & - & $0.26(1.00)$ \\
\hline (Prob) & . & $-1.22(0.22)$ & $-0.15(0.88)$ & $-2.41(0.02)$ & $-0.48(0.63)$ & $-1.11(0.27)$ & - & $-0.88(0.38)$ \\
\hline $\operatorname{AR}(1)$ & $0.655(0.51)$ & $-0.81(0.42)$ & $-1.62(0.11)$ & $-1.02(0.31)$ & $-1.07(0.31)$ & $-1.02(0.31)$ & - & $-1.77(0.08)$ \\
\hline $\operatorname{AR}(2)$ & 63 & 105 & 168 & 126 & 70 & 140 & 14 & 63 \\
\hline Gözlem & & & & & & & & \\
\hline
\end{tabular}


Sekiz sektörü bağımsız olarak ele alan Tablo 4 yukarıda tahmin edilen ve kabul edilebilirliği en yüksek model olan Model 1'deki değişkenleri içermektedir. Diğer bir ifadeyle bu sekiz denklemde bağımlı değişken olarak nakit akış döngüsü (NAD), bağımsız değişkenler olarak nakit akış döngüsünün bir dönem gecikmeli değeri (NAD(-1)), özsermaye karlılığ $1(\mathrm{OK})$, aktif karlılığ1 (AK), faiz ve vergi öncesi kar devir hızı (FVÖKDH), net işletme sermayesi devir hızı (NISDH), özsermaye devir hızı (ODH) ve aktif devir hızı (ADH) kullanılmıştır.

Tablo 4'teki modellerin her biri farklı gözlem sayısına sahiptir. Bu doğrultuda özellikle ormancılık sektörüne ait 14 adet panel veri ( 2 firma) olması bu tahminin güvenilir olmadığını göstermektedir. Diğer sektörlerde ise genel olarak veri sayısının yeterli olduğu ileri sürülebilir. Söz konusu 7 sektöre ait tahmin modellerinin ekonometrik testler açısından zayıf olduğu görülmektedir. Bu nedenle Tablo 4'ten genel eğilimlerin çıkarılması yaklaşımı tutarlıdır.

Tablo 4'te yer alan sonuçlara göre; "metal” sektöründe nakit akış döngüsünü belirleyen unsurlar özsermaye karlılığı ve özsermaye devir hızıdır. "Kimya" sektöründe nakit akış döngüsünün belirleyenleri ise nakit akış döngüsünün bir dönem gecikmeli değeri, faiz ve vergi öncesi kar devir hızı, net işletme sermayesi devir hızı, özsermaye devir hızı ve aktif devir hızıdır. Yine "makine" sektöründe nakit akış döngüsünün belirleyicileri nakit akış döngüsünün bir dönem gecikmeli değeri, aktif karlılığı ve aktif devir hızıdır. "Gıda" sektöründe nakit akış döngüsünün belirleyicileri ise nakit akış döngüsünün bir dönem gecikmeli değeri, faiz ve vergi öncesi kar devir hızı ve aktif devir hızıdır. Diğer taraftan "kağıt" sektöründe nakit akış döngüsünün belirleyicisi nakit akış döngüsünün gecikmeli değeridir. Bir diğer sektör olan "Çimento" sektöründe ise nakit akış döngüsünün belirleyicileri bir dönem gecikmeli nakit akış döngüsü, özsermaye devir hızı ve aktif devir hızıdır. Yukarıda da değinildiği üzere "ormancılık" sektörüne ait gözlem sayısı sınırlıdır. Bu nedenle söz konusu sektöre ilişkin sağlıklı yorumlar yapmak mümkün değildir. Son olarak "tekstil" sektöründe ise nakit akış döngüsünün belirleyicisi sadece bir dönem gecikmeli nakit akış döngüsüdür. Genel olarak değerlendirildiğinde ise yukarıda sektör analizine göre nakit akış döngüsünün belirleyicilerinin biri nakit akış döngüsünün bir dönem gecikmeli değeri diğeri de aktif devir hızıdır.

\section{Sonuç}

Finansal yönetim içerisinde işletme sermayesi yönetimi ve işletme sermayesi yönetimi içinde de nakit yönetimi çok önemli bir yere sahiptir. Nakit akış süresi sürekli bir döngü içerisinde devam eden işletme faaliyetleri açısından kritik öneme sahiptir. İşletmenin parasal yükümlülüklerini zamanında karşılayabilmesi ve faaliyetlerini kesintisiz devam ettirilebilmesi için nakit yönetiminde etkinlik sağlanması zorunludur. Literatürde nakit akış döngüsünün işletme karlılığ (performansı) üzerinde etkili olduğu görüşü yaygındır. Bu çalışma da nakit akış döngüsünün firma düzeyinde temel belirleyicisi ya da belirleyicileri nelerdir sorusuna yanıt aramaktadır.

Bunun için çalışmada ilk olarak nakit akış döngüsü ve diğer finansal oranlar arasındaki korelasyon tablosu oluşturulmuştıur. Daha sonra dinamik bir tahminleme modeli olan Sistem GMM panel regresyon tekniğiyle farklı bağımsız değişkenlerden oluşan beş model tahmin edilmiştir. Hemen ardından sektörel ayrıştıma yapılmıştır. Bu kısımda önce ortalama değerler ortaya konulmuş ve sonrasında her bir sektör için en uygun tahmin modeli üzerine kurulu Sistem GMM panel regresyon analizi yapılmıştır.

Korelasyon analizi sonuçlarına bakıldığında nakit akış döngüsü ile sırasıyla aktif devir hızı, aktif karlılığı ve özsermaye devir hızı arasında negatif yönlü ve istatistiksel açıdan anlamlı ilişki tespit edilmiştir. Sistem GMM panel regresyon analizi sonuçlarına göre ise Model 1'in en uygun tahmin modeli olduğu görülmüş ve bu modelde de nakit akış döngüsünü bir dönem gecikmeli nakit akış döngüsü, aktif karlılığ ve aktif devir hızının etkilediği sonucuna varılmıştır. Elde edilen sonuçlar literatür açısından yeni bulgulardır. Nitekim ilgili literatürde nakit akış döngüsü konusu daha ziyade nakit akış döngüsünün karlılık ya da kurumsal performans üzerine etkileri bağlamında 
incelenmiştir (Yücel ve Kurt, 2002; Anser ve Malik 2013; Jamal, Waseem ve Khan, 2014; Mun ve Jang, 2015; Cristea ve Cristea, 2018; Samosir, 2018). Bununla birlikte alternatif Sistem GMM panel regresyon modellerinin her birinde özellikle nakit akış döngüsünün bir dönem gecikmeli değerinin istatistiksel açıdan anlamlı olması dikkat çekicidir.

Sektörel olarak değerlendirildiğinde nakit akış süresinin Uyar (2009)'ın bulgularıyla aynı doğrultuda olduğu ve "metal" sektöründe en az, "tekstil" sektöründe en yüksek olduğu görülmüştür. Tekstil sektöründeki bu uzun nakit akış süresinin nedeni özellikle söz konusu sektördeki stok tutma süresinin nispeten uzun olmasıdır. Değinilen analizden ayrıca genel olarak işletme büyüklüğü arttıkça nakit akış süresinin de azaldığı sonucuna varılabilir. Diğer taraftan nakit akış döngüsü bileşenlerinin açıklanmasından sonra sektörel Sistem GMM panel regresyon analizi yapılmıştır. Söz konusu analize göre genel olarak nakit akış döngüsünü bir dönem gecikmeli nakit akış döngüsü ve aktif devir hızının önemli derecede etkilediği bulgulanmıştır. Gözlem kısıtının söz konusu olduğu yukarıdaki analizlerde diğer değişkenlerin etkisi ise sektörden sektöre değişmektedir.

Diğer taraftan bu çalışmadan daha sonra yapılacak olan ampirik çalışmalarda özellikle aktif yönetimi konusunun finansal performans üzerindeki etikilerinin araştırılması önerilmektedir.

Nihayetinde yukarıda yapılan analizlere göre imalat sanayi işletmelerinde nakit akış döngüsü süresi özellikle firmaların bir önceki dönem nakit akış döngüsü sürelerine bağlıdır. Diğer taraftan aktif büyüklüğü veya aktif yönetimi yine nakit akış döngüsü süresi üzerinde önemli derecede etkilidir. Buna göre işletmelerde özellikle duran varlıkların nasıl kullanıldığı ya da duran varlıklara ne ölçüde yatırım yapıldığı sorularına odaklanılmalıdır. Dahası bu çalışmada yapılan analizlere göre işletmeler büyüdükçe daha iyi bir nakit yönetimi gerçekleştirmektedirler. Bu da işletme büyüklüğü arttıkça daha istikrarlı bir karlılı1k sağlanmasının nedenlerinden biri olabilir. Kısacası, özellikle küçük işletmeler finansal performanslarını arttırmak için nakit yönetimi (alacak yönetimi, stok yönetimi ve borç yönetimi) konusunda daha hassas ve daha bilinçli olmalidırlar. 


\section{Kaynakça}

Akinyomi, O. J. (2014). Effect of Cash Management on Firm Profitability of Nigerian Manufacturing Firms. International Journal of Technology Marketing, 4(1), 129-140.

Ali, S., Rahman, A. U., Obaid, Z. (2017). Can Working Capital Cycle or Cash Conversion Cycle be Factored in Economic Performance of Pakistani Corporate Firms? The Journal Of Humanities \& Social Sciences, 25(1), 97-108.

Anser, R., Malik, Q. A. (2013). Cash Conversion Cycle and Firms' Profitability-A Study of Listed Manufacturing Companies of Pakistan. IOSR Journal of Business and Management, 8(2), 83-87.

Attari, M. A., Raza, K. (2012). The Optimal Relationship of Cash Conversion Cycle with Firm Size and Profitability. International Journal of Academic Research in Business and Social Sciences, 2(4), 189-203.

Bhutto, N. A., Abas, G., Rehman, M., Shah, S. M. M. (2011). Relationship of Cash Conversion Cycle with Firm Size, Working Capital Approaches and Firm's Profitability: A Case of Pakistani Industries. Pakistan Journal of Engineering, Technology \& Science, 1(2), 45-64.

Bolek, M., Kacprzyk, M., Wolski, R. (2012). The Relationship Between Economic Value Added and Cash Conversion Cycle In Companies Listed on The WSE. University of Information Technology and Management, 8(2), 1-10.

Chang, C. C. (2018). Cash Conversion Cycle and Corporate Performance. Global Evidence, International Review of Economics \& Finance, 56, 568-581.

Cristea, C., Cristea, M. (2018). Cash Conversion Cycle and Corporate Performance: Evidence From Romania. Annual Session of Scientific Papers, 1-4.

Deloof, M. (2003). Does Working Capital Management Affect Profitability of Belgian Firms? Journal of Business Finance \& Accounting, 30(3), 573-587.

Ebben, J. J., Johnson, A. C. (2011). Cash Conversion Cycle Management in Small Firms: Relationships with Liquidity, Invested Capital, and Firm Performance. Journal of Small Business \& Entrepreneurship, 24(3), 381-396.

Enqvist, J., Graham, M., Nikkinen, J. (2014). Impact of Working Capital Management on Firm Profitability in Different Business Cycles: Evidence from Finland. Research in International Business and Finance, 32, 36-49.

Filbeck, G., Krueger, T. M. (2005). An Analysis of Working Capital Management Results Across Industries. American Journal of Business, 20(2), 11-20.

Garanina, T., Petrova, O. (2015). Liquidity, Cash Conversion Cycle and Financial Performance: Case Of Russian Companies. Investment Management and Financial Innovations, 12(1), 90-100

Gentry, AJ. A., Vaidyanathan, R., Lee, H. W. (1990). A Weighted Cash Conversion Cycle. Financial Management, 19(1), 90-99.

Jamal, S., Waeem, S. N., Khan, S. (2014). Impact of Cash Conversion Cycle on Profitability of Sugar Sector in Pakistan. Asian Journal of Research In Banking and Finance, 4(3), 59-69.

Karadağl1, E. (2013). Profitability Effects of Cash Conversion Cycle: Evidence from Turkish Companies. Actual Problems of Economics, 3(141), 300-310.

Kaur, H. V., Singh, A. (2016). Relationship of Cash Conversion Cycle with Profitability: An Analysis of Power Sector in India. International Journal of Emerging Issue in Management and Technogoly, 1(1), s: 32-45. 
Konuk, F. ve Zeren, F. (2014). Is Cash Conversion Cycles Optimum in Turkish Listed FoodBeverage Firms? Theoretical and Applied Economics Volume, 21(12), 153-164.

Kroes, J. R., Manikas, A. S. (2014). Cash Flow Management and Manufacturing firmFnancial Performance: A Longitudinal Perspective. International Journal Production Economics, $148,37-50$.

Linh, N. T. P., Mohanlingam, S. (2018). The Effects of Cash Conversion Cycle on Profitability: An Insight Into The Agriculture and Food Industries in Thailand. Asian Journal of Business and Accounting, 11(1), s: 97-119.

Lyroudi, K. ve MacCarty, D. (1993). An Empirical Investigation of the Cash Conversion Cycle of Small Business Firms. Journal of Small Business Finance, 2(2), 139-161.

Mathuva, D. M. (2014). An Empirical Analysis of the Determinants of The Cash Conversion Cycle in Kenyan Listed Non-Financial Firms. Journal of Accounting in Emerging Economies, 4(2), 175-196.

Mun, S. G., Jang, S. S. (2015). Working Capital, Cash Holding and Profitability. International Journal of Hospitality Management, 48, s: 1-11.

Nobanee, H., Abdullatif, M., AlHajjar, M. (2011). Cash Conversion Cycle and Firm's Performance of Japanese Firms. Asian Review of Accounting, 19(2), 147-156.

Oseifuah, E. K., Gyekye, A. (2016). Cash Conversion Cycle Theory and Corporate Profitability: Evidence from Non-Financial Firms Listed on The Johannesburg Stock Exchange. Journal of Accounting and Management, 6(3), 37-51.

Richards, V. D., Laughlin, E. J. (1980). A Cash Conversion Cycle Approach to Liquidity Analysis. Financial Management, 9(1), 32-38.

Rizky, A., Mayasari, M. (2018). The Impact of Cash Conversion Cycle on Firm Profitability of Retail Companies. Journal of Applied Accounting and Taxation, 3(1), 73-78.

Ruyken, P. T. G., Wagner, S. M., Jönke, R. (2011). What is the Right Cash Conversion Cycle for Your Supply Chain? International Journal Services and Operations Management, 10(1), 13-29.

Samosir, F. C. (2018). Effect of Cash Conversion Cycle, Firm Size, And Firm Age to Profitability. Journal of Applied Accounting and Taxation, 3(1), 50-57.

Şen, M., Oruç, E. (2009). Relationship Between Efficiency Level of Working Capital Management and Return on Total Assets In ISE. International Journal of Business and Management, 4(10), 109-114.

Takon, S. M. (2013). Does Cash Conversion Cycle Have Impact on Return on Assets of Nigerian Firms? Research Journal of Finance and Accounting, 4(14), 34-43.

Talonpoika, A. M., Monto, S. Pirtilla, M., Karri, T. (2013). Modifying The Cash Conversion Cycle: Revealing Concealed Advance Payments. International Journal of Productivity and Performance Management, 63(3), 341-353.

Upadhyay, S. Sen, B., Smith, D. G. (2015). The Cash Conversion Cycle and Profitability: A Study of Hospitals in The State of Washington. The Journal of Health Care Finance, 1-9.

Uyar, A. (2009). The Relationship of Cash Conversion Cycle with Firm Size and Profitability: An Empirical Investigation in Turkey. International Research Journal of Finance and Economics, 24, 186-193.

Valahzaghard, M. K., Ghalhari, T. F. (2014). Relationship of Cash Conversion Cycle (Ccc) and Profitability of The Firm: Evidence From Tehran Stock Exchange. Journal of Finance and Accounting, 2(1), 137-148. 
Wang, B. (2019). The Cash Conversion Cycle Spread. Journal of Financial Economic, 1-26.

Wang, Y. J. (2002). Liquidity Management, Operating Performance, and Corporate Value: Evidence from Japan and Taiwan. Journal of Multinational Financial Management, 12, $159-16$.

Yasir, M., Majid, A., Yousaf, Z. (2014). Cash Conversion Cycle and its Impact Upon Firm Performance: An Evidence from Cement Industry of Pakistan. Global Business and Management Research: An International Journal, 6(1), 139-149.

Yazdanfar, D., Öhman, P. (2014). The Impact of Cash Conversion Cycle on Firm Profitability an Empirical Study Based on Swedish Data. International Journal of Managerial Finance, 10(4), 442-452.

Yücel, T., Kurt, G. (2002). Cash Conversion Cycle, Cash Management and Profitability: An Empirical Study on the Ise Traded Companies. The ISE Review, 6(22), 1-16.

Zakari, M., Saidu, S. (2016). The Impact of Cash Conversion Cycle on Firm Profitability: Evidence from Nigerian Listed Telecommunication Companies. Journal of Finance and Accounting, 4(6), 342-350. 